\title{
Composition of intraocular foreign bodies: experimental study of ultrasonographic presentation
}

\author{
Composição de corpos estranhos intraoculares: estudo experimental da apresentação ultrassonográfica
}

\author{
Márcio Augusto Nogueira Costa ${ }^{1}$, Patrícia Novita Garcia ${ }^{1}$, Letícia Fernandes Barroso ${ }^{1}$, Marco Antonio Ferreira ${ }^{2}$, Érika Araki Okuda ${ }^{1}$, Norma Allemann ${ }^{1}$
}

\begin{abstract}
Purpose: To investigate the reliability of ultrasound in determining the size and identify the sonographic features and artifacts generated by intraocular foreign bodies of different materials.

Methods: Experimental study using 36 enucleated porcine eyes. Fragments of nine different compositions (wood, glass, plastic, cardboard, iron, aluminum, lead powder and concrete) and similar dimensions ( $4 \mathrm{~mm}$ ) were implanted via sclera incision into the vitreous cavity of 36 porcine eyes, four eyes were used for each material. Ultrasound examination was performed in all eyes using the contact technique, conductive gel and 10-MHz transducer (EZScan, Sonomed).

Results: Considering the material fragments of gunpowder, lead, concrete, aluminum, wood and glass, the size determined by ultrasound was considered statistically similar to the actual size. The material iron presented ultrasound-determined dimension statistically smaller than its actual size. Cardboard and plastic materials showed ultrasound-determined measurements far greater than the actual. All fragments of intraocular foreign bodies demonstrated hyper-reflective interfaces, irrespective of their composition. Whereas the artifacts generated by different materials, it was found that the materials iron, aluminum and lead showed reverberation of great extent. The material wood showed no reverberation. The length of the reverberation artifact for the materials iron, glass, aluminum and cardboard was lower when compared to other materials. All materials presented posterior shadowing artifact, with the exception of aluminum.

Conclusion: Ultrasonography was considered a reliable technique to determine the size of intraocular foreign bodies in pigs, with little influence caused by its composition. Ultrasound artifacts generated were considered material-dependent and can assist the examiner to identify the nature of a foreign body of unknown etiology. Ultrasonography aided the surgeon to identify, locate and measure the intraocular foreign body, directing appropriate surgical planning.
\end{abstract}

Keywords: Eye foreign bodies/diagnosis; Eye foreign bodies/ultrasonography; Artifacts; Swine

\section{RESUMO}

Objetivo: Investigar a confiabilidade da ultrassonografia em determinar a dimensão e identificar as características ultrassonográficas e os artefatos gerados por corpos estranhos intraoculares de materiais diferentes.

Métodos: Estudo experimental, utilizando 36 olhos enucleados de origem suína. Fragmentos de nove diferentes composições (madeira, vidro, plástico, papelão, ferro, alumínio, chumbo, pólvora e concreto) e de dimensões similares (4 mm) foram implantados cirurgicamente via incisão escleral na cavidade vítrea de 36 ol hos porcinos, 4 olhos para cada tipo de material. O exame ultrassonográfico foi realizado em todos os olhos utilizando-se a técnica de contato, gel condutor e transdutor de $10 \mathrm{MHz}$ (EZScan, Sonomed).

Resultados: Considerando os fragmentos dos materiais pólvora, chumbo, concreto, alumínio, madeira e vidro, a dimensão determinada pela ultrassonografia foi considerada estatisticamente similar à dimensão real. O material ferro apresentou dimensão ultrassonográfica estatisticamente menor que sua dimensão real. Papelão e plástico demonstraram medida maior que o real. Todos fragmentos de corpos estranhos intraoculares demonstraram interfaces hiper-refletivas, independentemente da sua composição. Considerando os artefatos gerados pelos diferentes materiais, verificou-se que os materiais ferro, alumínio e chumbo apresentaram reverberação de grande extensão. O material madeira não apresentou reverberação. O comprimento do artefato de reverberação dos materiais ferro, vidro, alumínio e papelão foi menor quando comparado aos outros materiais. Todos materiais apresentaram artefato de sombreamento posterior, com exceção do alumínio.

Conclusão: A ultrassonografia foi considerada uma técnica confiável para determinar a dimensão de corpos estranhos intraoculares em porcinos, com pouca influência causada pela sua composição. Artefatos gerados à ultrassonografia foram considerados material-dependentes e podem auxiliar o examinador a identificar a natureza de um corpo estranho de etiologia desconhecida. O auxílio diagnóstico nestes casos permite ao cirurgião identificar, localizar e dimensionar o corpo estranho intraocular, orientando um planejamento cirúrgico adequado.

Descritores: Corpo estranho intraocular/diagnóstico; Corpo estranho intraocular/ ultrassonografia; Artefatos; Suínos

\section{INTRODUCTION}

The use of the ultrasonographic method for identification of an intraocular foreign body was reported in 1960 aiming diagnosis and monitoring of its surgical removal. Once in the eye, the foreign body (FB) may lodge in any of the ocular structures, which can generate important mechanical effects such as cataract formation, vitreous liquefaction, hemorrhage and retinal breaks. Regarding the composition of intraocular foreign bodies, the most frequent are: metal, glass, wood and plastic. The management and prognosis depends of the composition, location, size of the FB and the presence or not of inflammatory process and/or associated intraocular hemorrhage ${ }^{(1,2)}$.

The ultrasonographic findings of metallic intraocular foreign bodies (IOFBs) are similar, producing an echo of high density with posterior shadowing. The spherical IOFB have specific signals due to sound reverberation produced, causing an acoustic artifact at B-mode, known as "comet tail". Meanwhile, vegetal or organic nature IOFB, such as wood, may produce high reflectivity echoes although they could decrease over time due to decomposition process.

Submitted for publication: August 15, 2012

Accepted for publication: November 7, 2012

Experiment carried out at Experimental Surgical Center and Ultrasound Service, Department of Ophthalmology, Universidade Federal de São Paulo, São Paulo, SP, Brazil.

Physician, Department of Ophthalmology, Universidade Federal de São Paulo, São Paulo, SP, Brazil. 2 Veterinary Physician, Department of Ophthalmology, Universidade de Franca, Franca, SP, Brazil.

Funding: No specific financial support was available for this study

Disclosure of potential conflicts of interest: M.A.N.Costa, None; P.N.Garcia, None; L.F.Barroso, None; M.A.Ferreira, None; E.A.Okuda, None; N.Allemann, Travel/accommodations/meeting expenses by Quantel Medical Inc.

Correspondence address: Norma Allemann. Rua Olimpíadas, 134 - Conj. 51 - São Paulo (SP) 04551-000 - Brazil - E-mail: norma.allemann@pobox.com 
In the literature, there are few studies showing differences of generated artifacts considering different materials, including analysis of its dimensions determined by ultrasonography.

In a study performed in 1994, in Troina (Italy), it was found that echographic measurements of metallic intraocular foreign bodies were overestimated when compared to actual values, especially in foreign bodies of smaller diameter, with measurements of $2.0 \mathrm{~mm}$ and $2.2 \mathrm{~mm}^{(1)}$.

The current study aims to compare the actual dimensions to those obtained by ultrasonography and to characterize the generated acoustic artifacts of IOFBs from various materials and of similar sizes. It aims to investigate the reliability of ultrasonography in determining the dimension and identify the artifacts generated by IOFBs from different materials.

\section{METHODS}

Project number and responsible institution for notion of the Ethics Research Committee/Investigational Review Board: Ethics Research Committee CEP - UNIFESP, Protocol approved under number: 1695/11.

Thirty-six enucleated porcine eyes were used for this experimental study. The eyes were enucleated immediately after sacrifice at a local slaughterhouse and were kept in a refrigerator (1 hour) at a constant temperature of $+5^{\circ} \mathrm{C}$ until the implantation procedure of the foreign body and the ultrasonography evaluation. Fragments of 9 different materials such as wood, glass, plastic, cardboard, iron, aluminum, lead, powder and concrete, presenting similar measurements, approximately $4 \mathrm{~mm}$ of radial dimension, were used. In 4 eyes for each material type, fragments were inserted into the vitreous cavity through scleral incision positioned $4 \mathrm{~mm}$ posteriorly to limbus, with subsequent scleral incision sutures using 10-0 nylon monofilament sutures. Ultrasonography evaluation was then performed on each eye. The transducer was protected with a disposable glove during the exam, which was subsequently discarded.

The ophthalmic ultrasonography device used was the A- and B-mode EZScan (Sonomed) equipped with a 10-MHz transducer. Examination was performed by one echographer using contact technique and conductive gel.

The ophthalmic ultrasonography was acquired in axial, radial and transversal scans, in order to find the best representation of the referred foreign body. After all measurements, the images were recorded according to each material used.

For comparison of foreign bodies measures, an analysis of variance (ANOVA) was performed using the material type of FB as a factor under the measurement values made by ultrasonography (dependent variable). For comparisons between groups, Tukey post hoc tests were used. For all tests, the alpha value considered was 0.05 .

The IOFBs were evaluated with the 10-MHz transducer and $60 \mathrm{~dB}$ gain. Each FB was classified according to its reflectivity (high, medium and low) and the presence of artifacts. The artifacts could be classified as: reverberation (or echo duplication) and acoustic shadow (shadowing). The reverberation artifact was subjectively classified according to its length (Figure 1), i.e. the maximum distance that artificial echoes (reverberation) are distant from the real object (the real fragment) and subdivided into large, medium and small regarding the size of the FB. It was also subjectively classified according to their size, i.e. the size of the $1^{\text {st }}$ artifact interface generated by a FB and subdivided into larger, smaller or equal to the real object.

\section{RESULTS}

Measures of FBs from different materials were compared by a general linear model (ANOVA, one factor), followed by post hoc tests for specific comparisons. Significant differences were found among the actual measures ( $F=21.76, p<0.001)$ and measures obtained by ultrasonography for each material used.
Estimative measure of each fragment was performed and results are shown in table 1. The highest mean dimension was obtained from plastic and cardboard materials with $5.325 \mathrm{~mm}$ and $4.950 \mathrm{~mm}$ respectively, standard error of $0.145 \mathrm{~mm}$. The iron material showed the smallest mean dimension with 3.125 and standard error of $0.145 \mathrm{~mm}$

In table 2, fragments of different compositions were grouped into statistically homogeneous subgroups given by the Tukey b test, considering the mean measurements obtained from each fragment to ultrasonography. The subgroups were considered homogeneous in terms of statistics, while into the subgroup the measures could be considered equal.

The ultrasonographic measurements obtained from iron material were significantly lower than the actual measurements. The cardboard and plastic materials presented ultrasonographic measurements significantly larger than the real ones, while for other materials, differences in ultrasonographic measurements were not significantly different from actual measurements.

In the present study, the glass material showed high reflectivity and reverberation with slightly smaller size than the actual FB that decreased in size progressively if positioned farther from the FB. The artifact had medium length and ended abruptly. Moreover, it also generated the posterior acoustic shadowing artifact.

The plastic material did not show homogeneous thickness and in the portion in which it was thicker, artifact was generated. In the

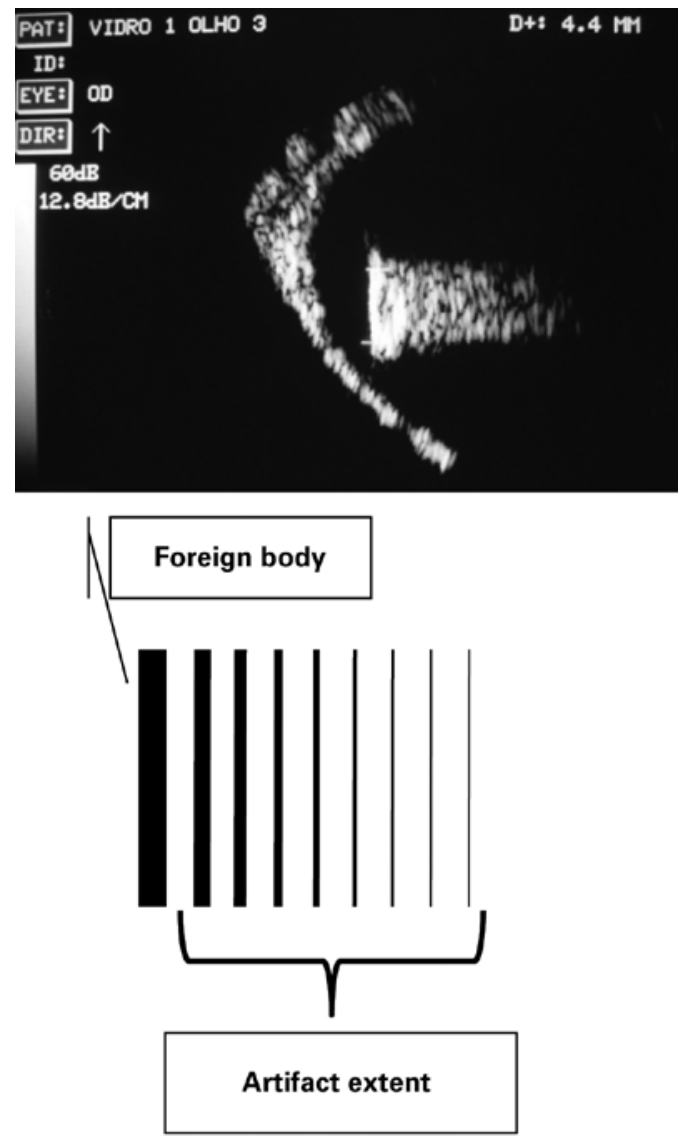

Figure 1. A porcine eye $10 \mathrm{MHz}$ ultrasonography with a glass foreign body in vitreous cavity, actual size of measured object $=4.4 \mathrm{~mm}$. Observe the reverberation artifact, interfaces arranged to the right of the real object, which gradually loses strength and intensity. The corresponding diagram demonstrates how the extent of the artifact interfaces caused by a foreign body to ultrasonography can be interpreted. 
Table 1. Mean size, standard error and confidence interval (95\%) of the fragments used as intraocular foreign bodies in an experimental study in porcine eyes, classified according to the material of its composition

Estimative measures of fragments used as intraocular foreign bodies ( $\mathrm{mm}$ )

\begin{tabular}{lcccc}
\hline \multirow{2}{*}{$\begin{array}{l}\text { Composition } \\
\text { material }\end{array}$} & Mean & $\begin{array}{c}\text { Standard } \\
\text { error }\end{array}$ & Lower limit & Upper limit \\
\cline { 4 - 5 } Wood & 3.925 & 0.145 & 3.617 & 4.216 \\
Glass & 4.075 & 0.145 & 3.767 & 4.366 \\
Plastic & 5.325 & 0.145 & $\mathbf{5 . 0 1 7}$ & 5.616 \\
Cardboard & 4.950 & 0.145 & 4.642 & 5.241 \\
Iron & 3.125 & 0.145 & $\mathbf{2 . 8 1 7}$ & 3.416 \\
Aluminum & 4.150 & 0.145 & 3.842 & 4.441 \\
Lead & 4.150 & 0.145 & 3.842 & 4.441 \\
Concrete & 4.200 & 0.145 & 3.892 & 4.491 \\
\hline
\end{tabular}

Table 2. Representation of 3 subgroups considered statistically homogeneous given by Tukey $b$ test, considering the mean measurements obtained from ultrasonography of different materials of composition from intraocular foreign bodies in an experimental study in porcine eyes

\begin{tabular}{|c|c|c|c|c|}
\hline \multicolumn{5}{|c|}{ Measurements of the fragments } \\
\hline \multirow[b]{2}{*}{$\begin{array}{l}\text { Composition } \\
\text { material }\end{array}$} & \multirow[b]{2}{*}{$\begin{array}{c}\text { Amount } \\
\text { of eyes }\end{array}$} & \multicolumn{3}{|c|}{ Subgroups } \\
\hline & & $\begin{array}{c}1 \\
\text { (smaller) }\end{array}$ & $\underset{\text { (similar) }}{2}$ & $\begin{array}{c}3 \\
\text { (larger) }\end{array}$ \\
\hline Wood & 4 & & 3.925 & \\
\hline Glass & 4 & & 4.150 & \\
\hline Plastic & 4 & & & 5.325 \\
\hline Cardboard & 4 & & & 4.950 \\
\hline Iron & 4 & 3.125 & & \\
\hline Aluminum & 4 & & 4.150 & \\
\hline Lead & 4 & & 4.075 & \\
\hline Concrete & 4 & & 4.200 & \\
\hline
\end{tabular}

thinner portion, no artifact was identified with the 10-MHz transducer. The plastic material was hyper-reflective to ultrasonography.

The cardboard material presented, at the ultrasonographic evaluation, high reflectivity and reverberation with medium length, which ended abruptly. The size of the artifact (reverberation) was slightly smaller than the real size of the object. A posterior shadowing artifact was also observed in this type of material.

The fragment of wood material presented high reflectivity and has not generated reverberation artifact, however, it caused the posterior shadowing artifact.

The concrete material showed high reflectivity and a slight reverberation that had already started with larger size than the actual fragment. It had a fait posterior acoustic shadowing. The concrete foreign bodies were more concentrated in the anterior vitreous cavity.

The iron material showed hyper-reflectivity and reverberation with large extent and initial size smaller than the actual fragment (Figure 2), decreasing progressively, recalling the appearance of "comet tail". There was a small acoustic shadow artifact.

The aluminum material presented itself as hyper-reflective and with reverberation similar to iron ("comet tail"). No posterior shadowing artifact was generated by aluminum material.

The lead material presented itself as hyper-reflective to the ultrasonography. The initial reverberation showed the same size of the
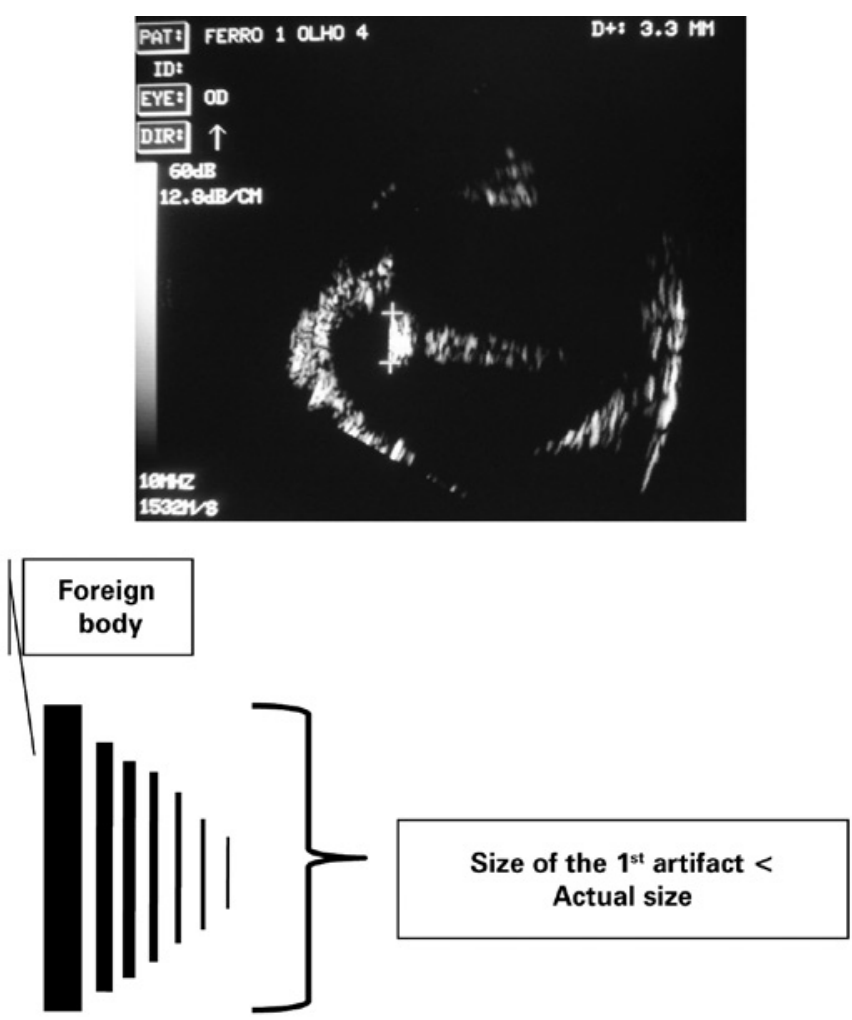

Figure 2. A porcine eye $10 \mathrm{MHz}$ ultrasonography with iron foreign body into the vitreous cavity, actual size of the measured object $=3.3 \mathrm{~mm}$. Observe the reverberation artifact, interfaces arranged to the right of the real object, which gradually loses strength and intensity. Note that the size of the $1^{\text {st }}$ artifact interface generated by iron is smaller than the real object. The corresponding diagram represents the size of the $1^{\text {st }}$ artifact interface generated by a foreign body in the ultrasonography examination, which is smaller than real object (foreign body).

actual fragment until a certain distance and subsequently its attenuation was observed (Figure 3). Different from iron and aluminum, which generated a reverberation that initially had already showed smaller size than the real object. The posterior shadowing artifact was observed.

The powder material presented itself as hyper-reflective to ultrasonography, although without posterior shadowing and reverberation. The powder material, due to its presentation in the form of powder presented an irregular shape to ultrasonography, due to its dispersion in the vitreous. It was not possible to perform the dimensioning of foreign bodies of powder material, therefore, this material was excluded from comparative statistical evaluation of this parameter.

In all the examined eyes, conclusions related to ultrasonographic dimensions of the fragments and to generated artifacts were obtained from echograms performed with proven perpendicularity of transducer incidence in relation to the tested fragment.

\section{DISCUSSION}

Penetrating injuries with retention of IOFBs are considered an important cause of ocular complications and potential risks of blindness ${ }^{(1-3)}$. In Brazil, among the traumatic diseases, the ocular trauma caused by FB represents the vast majority of attendances. The male gender is more affected than female, and the most affected age group corresponds to the age of greater professional productivity, i.e., from 16 to 45 years old(3)

The prognosis associated with the post-traumatic final visual acuity by intraocular foreign body (IOFB) and the risk of endophthal- 
mitis will depend on the size and type of the foreign body, presence and location of retinal lacerations, preoperative visual acuity and the time after trauma occurrence required to remove the IOFB. Wounds larger than $3 \mathrm{~mm}$ and FBs in posterior segment increase the risk of retinal injury and retinal detachment ${ }^{(4)}$. According to a study conducted in Germany ${ }^{(5)}$, the removal of IOFB in less than 24 hours from the trauma occurrence significantly decreases the risk of infectious endophthalmitis from $13.4 \%$ to $3.5 \%$. The same study reported that the material type is an important independent risk factor for complications. Fifty percent (50\%) of eye injuries by foreign bodies from vegetal origin, such as wood, had the complication of infectious endophthalmitis. In trauma associated with foreign bodies of metallic origin, the risk was considered low, with rates of $4.1 \%{ }^{(3-7)}$.

In penetrating trauma with foreign body, which may occur dense vitreous hemorrhage or severe anatomic disruption after trauma, there is a difficulty in identifying an IOFB. The method of ophthalmic ultrasonography is commonly used for evaluating traumatized eyes in order to identify lesions associated with trauma and in search of IOFBs, may be performed by all ophthalmologists ${ }^{(8,9)}$. If a FB is identified, it is important to obtain data on this fragment: location, size and echography characteristic so that it is possible to infer about its composition. Composition of IOFB can influence on the risk of endophthalmitis rate, of complications related to metallic foreign bodies and in scheduling of surgical removal(9).

Importantly, a controlled experimental study like the present one, contains information of location, size and composition of IOFB.
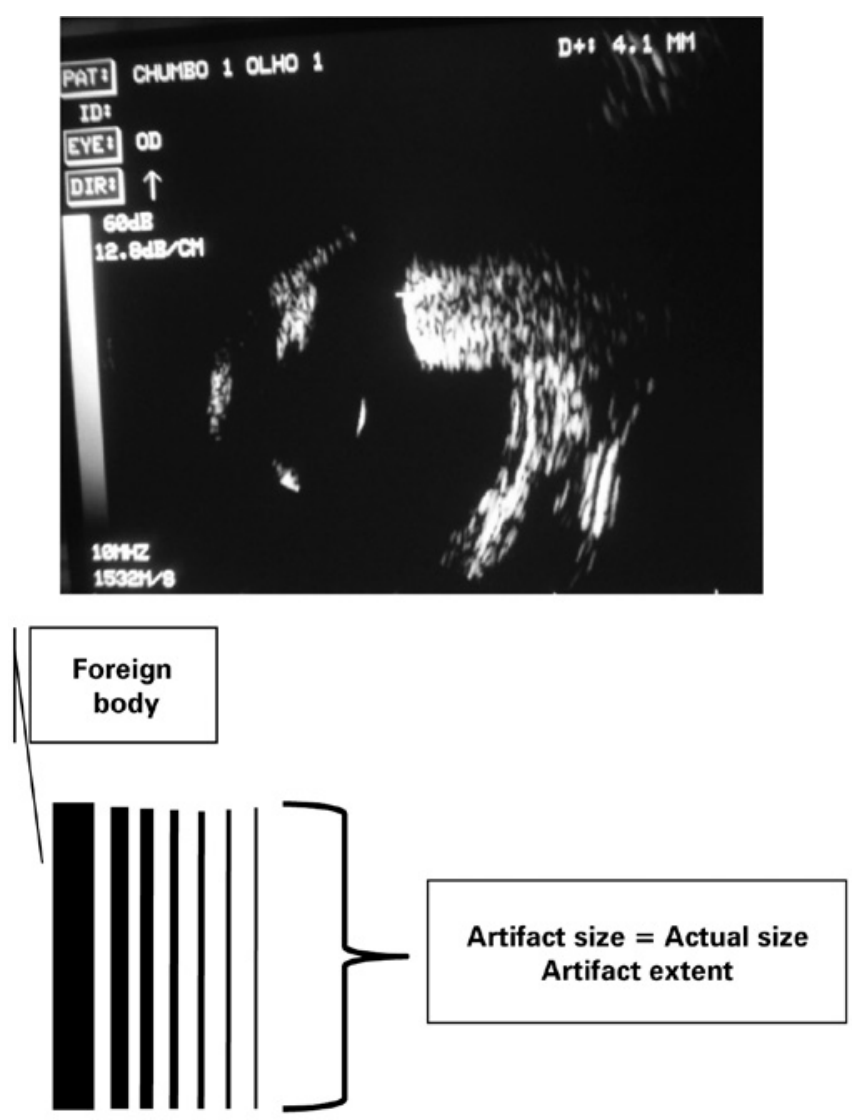

Figure 3. A porcine eye $10 \mathrm{MHz}$ ultrasonography with lead foreign body into the vitreous cavity, actual size of measured object $=4.1 \mathrm{~mm}$. Observe the reverberation artifact, interfaces arranged to the right of the real object, which remain with the same size of the real object. The corresponding diagram represents the size of artifact interfaces caused by a foreign body in the ultrasonography, which corresponds to the same size as the real object (foreign body).
Moreover, as the means of implementation of FB was controlled by surgical incision and post-mortem, the risk of associated lesions, such as hemorrhage or rupture of the lens could be eliminated. Thus, the ultrasonography was being held in appropriate technical conditions to identify FB and to establish an echogenicity pattern and artifacts for each composition.

The use of swine as experimental model is referred in Medicine since $1540^{(10)}$. Swine are used in research based on application or improvement of ophthalmic surgical techniques as well as experimental models of ocular diseases. The anatomical structure and the porcine eye dimensions differ a little in comparison to the human eye ${ }^{(11)}$, considering the cornea, anterior chamber, iris, ciliary body, lens, vitreous body and complex retina-choroid-sclera. The cornea, iris, ciliary body, anterior and posterior capsules of the lens and the posterior wall of the eye of these animals present at ultrasonography, as in human, as reflective interfaces; and the anterior chamber and the vitreous cavity have homogeneous anechoic content free of reflective interfaces in normal situations. The speed of sound wave propagation by aqueous humor and vitreous humor is $1,532 \mathrm{~m} / \mathrm{s}$ in human and 1,540 m/s in porcine eyes. Thus, the ocular ultrasonographic swine evaluation has similarities to that of human, thus enabling the use of these animals as an experimental model ${ }^{(11)}$.

The present study reinforces the importance of adequately evaluate the echographic characteristics of each material and points out to what type of material in its composition could generate a significant difference between its actual size and the size obtained by ultrasonography.

The ultrasonographic measurements of fragments from iron material were significantly lower than the actual ones. Cardboard and plastic materials presented ultrasonographic measurements significantly higher than the actual ones, while for the other material differences in ultrasonographic measurements were not significantly different from the actual value (Figure 4).

In the study performed in Italy ${ }^{(1)}$ in 1994, different measurements and fragments were used and only 1 shape (spherical) and 1 material type (metal). The study showed that ultrasonography may overestimate the actual values, especially in smaller FBs with measurements of $2.0 \mathrm{~mm}$ and $2.2 \mathrm{~mm}$. In the present study, the fragments used presented a measure (about $4 \mathrm{~mm}$ ), greater than referred by Cascone et al. It was also used different materials of fragments composition with non-standardized shapes, which might have caused significant differences (Table 3). Cascone et al. ${ }^{(1)}$ used only spherical shaped frag-

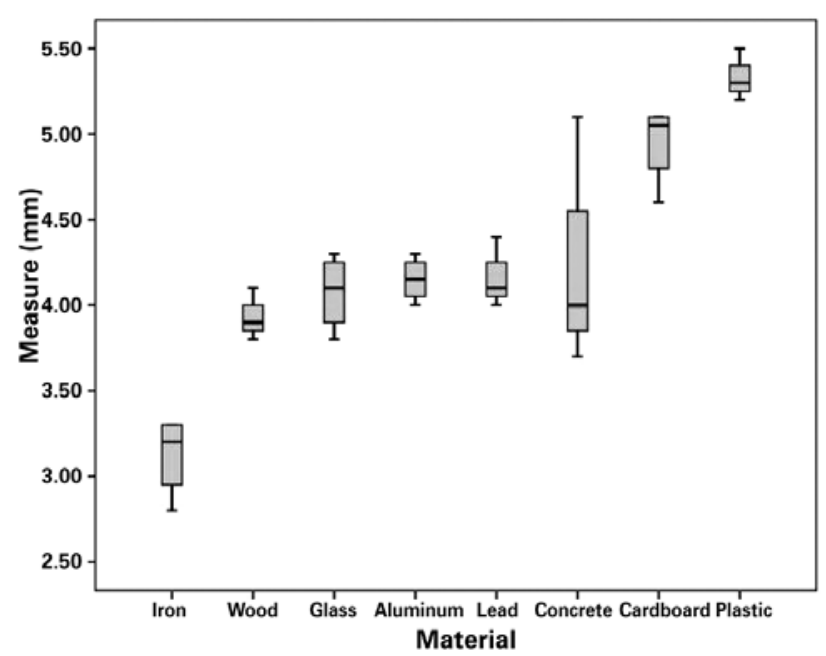

Figure 4. Box plot graph of ultrasonographic measurements obtained (median, interquartile range, minimum and maximum values) of each fragment used as intraocular foreign body in the experimental study in relation to their different composition materials. 
Table 3. Comparison between actual measurement and measurement obtained from ultrasonography of each intraocular fragment from different materials used in an experimental study in porcine eyes

\begin{tabular}{|c|c|c|c|c|c|}
\hline \multirow{2}{*}{$\begin{array}{l}\text { Composition } \\
\text { material }\end{array}$} & \multirow{2}{*}{$\begin{array}{c}\text { Actual } \\
\text { measurement (mm) }\end{array}$} & \multicolumn{4}{|c|}{ Ultrasonographic measurement (mm) } \\
\hline & & Eye 1 & Eye 2 & Eye 3 & Eye 4 \\
\hline Wood & 4.2 & 4.1 & 4.3 & 4.1 & 4.0 \\
\hline Glass & 4.1 & 4.1 & 4.3 & 4.4 & 3.9 \\
\hline Plastic & 4.0 & 5.5 & 5.2 & 5.3 & 5.3 \\
\hline Cardboard & 4.1 & 5.2 & 4.7 & 5.2 & 5.1 \\
\hline Iron & 4.0 & 3.1 & 2.8 & 3.3 & 3.3 \\
\hline Aluminum & 4.2 & 4.2 & 4.3 & 4.4 & 4.5 \\
\hline Lead & 4.0 & 4.1 & 4.1 & 4.0 & 4.4 \\
\hline Powder & 4.2 & Measurement not obtained & Measurement not obtained & Measurement not obtained & Measurement not obtained \\
\hline Concrete & 4.2 & 4.2 & 5.3 & 3.9 & 4.2 \\
\hline
\end{tabular}

Table 4. Ultrasonographic characteristics of fragments from different composition materials implanted into the vitreous cavity in an experimental study, considering reflectivity and generated artifacts (reverberation and acoustic shadowing)

\begin{tabular}{lcccc}
\hline & & \multicolumn{2}{c}{ Reverberation } & \\
\cline { 3 - 4 } Material & Reflectivity & Extent & Size & Acoustic shadowing \\
\hline Wood & High & Absent & Absent & Present \\
Glass & High & Medium & Smaller & Present \\
Plastic & High & Small & Smaller & Present \\
Cardboard & High & Medium & Smaller & Absent \\
Iron & High & Large & Smaller & Present (discrete) \\
Aluminum & High & Large & Smaller & Absent \\
Lead & High & Large & Equal & Present \\
Powder & High & Absent & Absent & Absent \\
Concrete & High & Small & Greater & Absent (discrete) \\
\hline
\end{tabular}

ments, but it was established that foreign bodies of different shapes could cause a variety of measures, according to the object orientation in the vitreous body.

In regard to echographic characteristics of various materials, we noted that they all showed hyper-reflectivity. The iron, aluminum and lead materials showed reverberation with great extent, unlike concrete material with small extent reverberation. The wood foreign bodies, however, did not present reverberation to ultrasonography. Importantly, the residence time of wood inside the eye influences the material consistency, as could occur fragment hydration with modification of their acoustic characteristics. Regarding the size of the reverberation artifact, glass, aluminum, cardboard and iron materials showed reverberation with smaller size than the fragment. For lead material, reverberation showed the same size as the actual fragment. All materials generated acoustic shadowing, except aluminum. The iron and concrete materials, however, showed a discrete acoustic shadowing (Table 4) There is no reference to reverberation characteristics in different materials of IOFB in the literature for comparability of this study. In the literature, the echographic findings of metallic foreign bodies are similar producing a very dense highly reflective echo that remains with low gain ${ }^{(6)}$ and usually causes a posterior shadowing ${ }^{(12-14)}$.

In our study, we observed that the acoustic shadowing is more evident in IOFB that are located closest to the wall and less evident when located further away from it. If they had been implanted closer to the ocular wall, they could have caused greater shadowing artifact.
Thus, knowing the acoustic differences of each potential material component of an IOFB in order to characterize it and know what materials types are capable to generate an artifact mistaken interpretation of its dimensions to ultrasonography will help to interpret ultrasonographic evaluation and thus provide appropriate planning of surgical procedures for removal of IOFB of the human being, whether through limbal or pars plana incisions, and will assist in evaluating the risk of endophthalmitis or associated inflammation that can be related to the nature of $\mathrm{FB}$.

Accurate workup in cases of trauma with retention of IOFB can help to resolve the framework sooner, aiming to lower complication risk, identifying best practice and establishing a visual prognosis.

\section{REFERENCES}

1. Cascone G, Filipello M, Ferri R, Scimone G, Zagami A. B-scan echographic measurement of endobulbar foreign bodies. Ophthalmologica. 1994;208(4):192-4.

2. Silva FM, Santos Júnior EC, Nóbrega MJ. Corpos estranhos intra-oculares: análise de 22 casos. ACM Arq Catarin Med. 2005:34(1):34-7.

3. Araújo AA, Almeida DV, Araújo VM, Góes MR. Urgência oftalmológica: corpo estanho ocular ainda como principal causa. Arq Bras Oftalmol. 2002;65(2):223-7.

4. Zhang Y, Zhang M, Jiang C, Qiu HY. Intraocular foreign bodies in China: clinical characteristics, prognostic factors, and visual outcomes in 1,421 eyes. Am J Ophthalmol. 2011;152(1):66-73.e1.

5. Jonas JB, Knorr HL, Budde WM. Prognostic factors in ocular injuries caused by intraocular or retrobulbar foreign bodies. Ophthalmology. 2000;107(5):823-8. Comment in Ophthalmology. 2000;107(5):821-2.

6. Ehlers JP, Kunimoto DY, Ittoop S, Maguire JI, Ho AC, Regillo CD. Metallic intraocular foreign bodies: characteristics, interventions, and prognostic factors for visual outcome and globe survival. Am J Ophthalmol. 2008;146(3):427-33.

7. Greven CM, Engelbrecht NE, Slusher MM, Nagy SS. Intraocular foreign bodies: management, prognostic factors, and visual outcomes. Ophthalmology. 2000;107(3): 608-12. Comment in Ophthalmology. 2001;108(1):9-10.

8. Chandra A, Mastrovitch T, Ladner H, Ting V, Radeos MS, Samudre S. The utility of bedside ultrasound in the detection of a ruptured globe in a porcine model. West $J$ Emerg Med. 2009;10(4):263-6.

9. Coleman DJ, Woods S, Rondeau MJ, Silverman RH. Ophthalmic ultrasonography. Radiol Clin North Am. 1992:30(5):1105-14. Review.

10. Mariano M. Minisuíno (minipig) na pesquisa biomédica experimental. O Minipig br1. Acta Cir Bras. 2003;18(5):387-91.

11. Dyce KM, Sack WO, Wesing CJ. Os órgãos dos sentidos. In: Dyce KM, Sack WO, Wesing CJ. Tratado de anatomia veterinária. 2a Ed. Rio de Janeiro: Guanabara Koogan; 1997. p.258-76.

12. Baillif S, Paoli V. [Open-globe injuries and intraocular foreign bodies involving the posterior segment]. J Fr Ophtalmol. 2012;35(2):136-45. French.

13. Obuchowska I, Sidorowicz A, Napora KJ, Mariak Z. [Clinical characteristics of penetrating ocular injuries with intraocular foreign body. Part II. Diagnostics and treatment]. Klin Oczna. 2010;112(1-3):77-81. Polish.

14. Ambartsumian AR. [Potential of ultrasound biomicroscopy in diagnosis of ocular trauma with intraocular metallic foreign bodies]. Vestn Oftalmol. 2011;127(4):29-33. Russian. 